\title{
Cultura tributaria como estrategia para disminuir la evasión fiscal en Ecuador
}

Fecha de recepción: 06-01-2021 • Fecha de aceptación:02-02-2021 • Fecha de publicación: 10-02-2021

Renato Estuardo Paredes Cruz ${ }^{1}$ Universidad Estatal de Bolívar, Ecuador renato.paredes@ueb.edu.ec https://orcid.org/0000-0003-1100-8596

Galo Hernán García Tamayo² Instituto Superior Tecnológico España, Ecuador galoh.garciat@iste.edu.ec https://orcid.org/0000-0002-2268-2730

\section{RESUMEN:}

La evasión tributaria se refiere a maniobras utilizadas por los diferentes contribuyentes para evadir o eludir sus impuestos de manera total o parcial y, que por ley están obligados a hacerlo. El impacto que esto genera en la economía ecuatoriana es demasiado relevante, por cuanto los precios del petróleo han bajado, dejando que el ingreso tributario se convierta en uno de los rubros más importantes del presupuesto general del Estado. El objetivo del presente trabajo investigativo es determinar las causas principales por las cuales los ciudadanos que realizan actividades económicas (contribuyentes) tratan de eludir y/o evadir sus responsabilidades en lo concerniente al pago de impuestos en el Ecuador. Se utilizó el método analítico-sintético para la elaboración del fundamento científico, apoyados en encuestas y entrevistas para representar el fenómeno y analizar las causas y efectos del área problemática. Entre los resultados obtenidos tenemos que la mayor parte de los entrevistados aseguran no cumplir con su obligación tributaria por desconocimiento; además se determinó que, en la ciudad predominan dos tipos de evasión tributaria: la informalidad y la no emisión de comprobantes de venta al momento de realizar una transacción económica. 
PALABRAS CLAVE: cultura tributaria, evasión fiscal, impuestos, ingresos tributarios, presupuesto general del Estado.

\begin{abstract}
Tax evasion refers to maneuvers used by different taxpayers to evade or avoid their taxes in whole or in part, and which by law they are obliged to do so. The impact that this generates in the Ecuadorian economy is too relevant, since oil prices have dropped, leaving the tax revenue to become one of the most important items of the general budget of the State. The objective of this research work is to determine the main causes for which citizens who carry out economic activities (taxpayers) try to evade and/or avoid their responsibilities concerning the payment of taxes in Ecuador. The analytical-synthetic method was used for the elaboration of the scientific basis, supported by surveys and interviews to represent the phenomenon and analyze the causes and effects of the problem area. Among the results obtained we have that most of the interviewees claim not to comply with their tax obligations due to lack of knowledge; it was also determined that two types of tax evasion predominate in the city: informality and the non-issuance of sales receipts at the time of an economic transaction.
\end{abstract}




\section{Introducción}

La evasión fiscal ocurre cuando un ciudadano viola las normas jurídicas de manera consciente, deliberada o de manera abierta, o por desconocimiento, tal como los vendedores ambulantes. La evasión fiscal en América Latina ha sido la regla en la región, ya que en estas economías es frecuente según Chelala \& Giarrizo (2014) "que la economía informal o no registrada tenga un tamaño similar o mayor a la economía registrada" (p. 272), siendo esta informalidad un peso para los gobiernos. Quintanilla de la Cruz (2014) manifiesta que de acuerdo a cifras de la Comisión Económica para América Latina (CEPAL) y, la Superintendencia Nacional de Aduanas y de Administración Tributaria (SUNAT), Ecuador es uno de los países que tiene las tasas más altas de evasión en la región con el $32 \%$. Perú alcanza una tasa de $34.7 \%$, Chile y Uruguay el $18 \%$, Argentina y México $20 \%$ y, Colombia $22 \%$. Por encima de Perú se encuentra Venezuela donde la evasión alcanza $66 \%$ (p. 84).

Tabla 1

Clasificación países América Latina según nivel de carga tributaria y el PIB per cápita

\begin{tabular}{|c|c|c|c|c|}
\hline \multicolumn{5}{|c|}{$\begin{array}{l}\text { PIB per cápita promedio 1990-2009 } \\
\text { (USD constantes de 2000) }\end{array}$} \\
\hline & & $\begin{array}{c}\text { Alto (mayor a } \\
\text { USD 3.903) }\end{array}$ & $\begin{array}{l}\text { Media (USD } \\
2.602 \text { a } 3.903 \text { ) }\end{array}$ & $\begin{array}{c}\text { Bajo (menor a } \\
\text { USD 2.602) }\end{array}$ \\
\hline \multirow{3}{*}{ 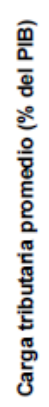 } & Alta (mayor a $19,5 \%$ ) & $\begin{array}{l}\text { Argentina, } \\
\text { Uruguay. }\end{array}$ & Brasil & --- \\
\hline & $\begin{array}{l}\text { Media (entre } 13,0 \% \\
\text { y } 19,5 \%)\end{array}$ & $\begin{array}{l}\text { Chile, Costa } \\
\text { Rica, Panamá, } \\
\text { Venezuela. }\end{array}$ & Colombia & $\begin{array}{l}\text { Bolivia, } \\
\text { Honduras, } \\
\text { Nicaragua, } \\
\text { Perú. }\end{array}$ \\
\hline & Baja (menor a 13,0\%) & México & $\begin{array}{l}\text { República } \\
\text { Dominicana }\end{array}$ & $\begin{array}{l}\text { Ecuador, } \\
\text { El Salvador, } \\
\text { Guatemala, } \\
\text { Paraguay. }\end{array}$ \\
\hline
\end{tabular}

Fuente: Quintanilla de la Cruz (2014) - Base de datos de la CEPAL

Uno de los principales factores que se interpone en la obtención de ingresos por parte del Estado es la evasión tributaria, también llamada evasión fiscal que según el autor Raymond (1997) es "la acción de efectuar fraude, evitar el pago de un impuesto, sea este parcial o total" (p. 76). Esto genera una diferencia entre lo recaudado y lo que realmente se debió recaudar, ocasionando un déficit en el presupuesto general del estado.

Existen algunos componentes por los cuales los contribuyentes se resisten a pagar sus impuestos, Castañeda (2015) señala los siguientes:

- La satisfacción con la intervención del Estado

- El sentido de responsabilidad social y solidaridad 
- Las normas éticas, el altruismo e incluso la nacionalidad (p.110).

Para la autora Del Valle (2010), los componentes que obligan a evadir impuestos a los contribuyentes en América Latina son:

- Carencia de conciencia tributaria

- Sistema tributario poco transparente

- Administración tributaria poco flexible

- Bajo riesgo de ser detectado

- Altas alícuotas

- La inflación (p. 140).

Continuando con el informe de la CEPAL, la carga tributaria de Ecuador fue del 19,7\% en el 2010, la cuarta más alta de la región atrás de Argentina, Brasil y Uruguay. En el 2007 la carga tributaria del país era del $14,4 \%$. Esta cifra ha sido objetada por funcionarios del Servicio de Rentas Internas (SRI), quienes afirman que se ha llegado solo al 15\% y que es una de las más bajas de la región.

El reporte destaca que en varios países los ingresos fiscales procedentes de recursos naturales no renovables siguen siendo muy importantes como porcentaje del total de los ingresos, toda vez que representan más de $30 \%$ del total en Bolivia, Ecuador, México y Venezuela, por lo que nace la pregunta ¿Qué pasará si los precios de las materias primas bajan? o, ¿Qué pasará cuando las materias primas se agoten? Gómez (2016), al respecto indica que los sistemas tributarios en esta región se han mostrado incapaces de resolver importantes debilidades estructurales con relación al nivel de recursos que efectivamente recaudan, a sus efectos sobre eficiencia económica y, muy especialmente a su impacto contributivo. Uno de estos obstáculos está dado por el elevado nivel de incumplimiento tributario por parte de los contribuyentes nacionales y extranjeros (p.7).

Según el Centro de Estudios Fiscales, la recaudación tributaria se incrementó en un 143\% desde el inicio del gobierno de Rafael Correa y que, según estimaciones de la autoridad tributaria, cerrará en alrededor de USD 11.000 millones. Esta se basa en un principio de equidad que menciona que el que más tiene más paga; sin embargo, en Ecuador históricamente se ha manejado la evasión tributaria como una estrategia empresarial. 


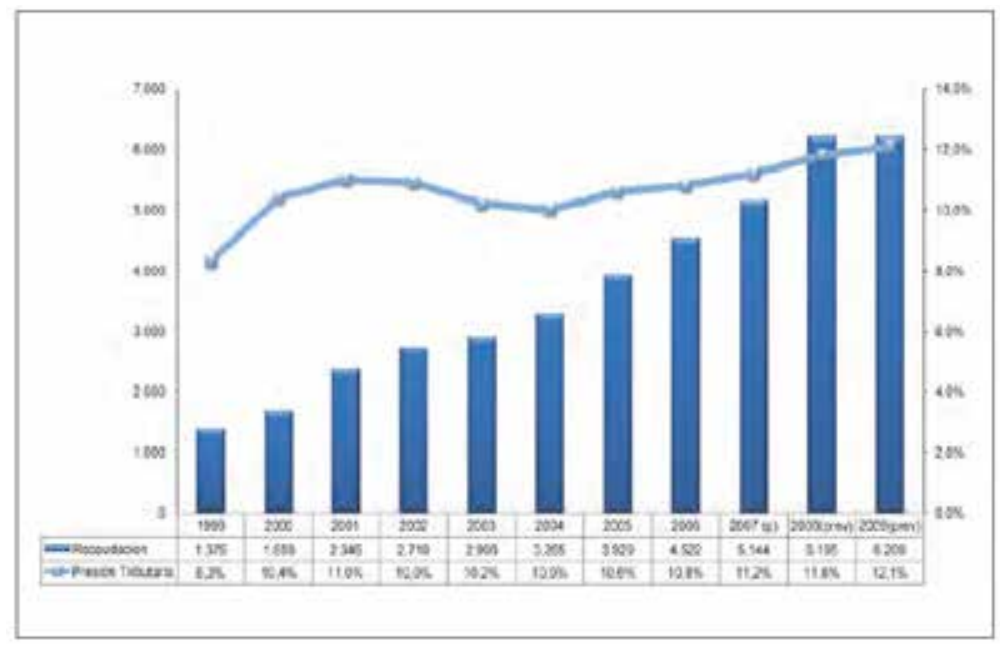

Figura 1. Evolución de la presión fiscal en Ecuador (en millones de dólares y en porcentajes)

Fuente: Centro de Estudios Fiscales

En la Figura 1 se puede apreciar una importante presión fiscal acentuada en los últimos años. Sin embargo, y a pesar de los esfuerzos que ha realizado el gobierno conjuntamente con el SRI, la evasión fiscal en Ecuador sigue siendo un problema. Según datos publicados por diario El Telégrafo, de un estudio realizado por el colegio de Economistas de Pichincha: "el país pierde entre $\$ 300$ y $\$ 400$ millones anuales por evasión fiscal. Esto equivale al $50 \%$ de la vialidad que se ha invertido en el país del periodo 2007 al 2015 dando un total de $\$ 8.512$ millones".

En cuanto a la brecha fiscal, Castro (2015) la define como "la diferencia que existe entre lo que el estado recaudaría si los contribuyentes cumplieran estrictamente las normas y la que realmente ingresó al fisco" (p.20). Ante esta situación, Romo (2015) señala que en los últimos siete años el Ecuador ha experimentado cambios importantes en el aspecto tributario, en dónde se han implementado diez reformas con el único afán de incrementar los ingresos tributarios. Así mismo, este autor señala que es importante mencionar que una reforma tributaria no solo busca crear, modificar, eliminar impuestos, aprobar o reducir tarifas, aplicar incentivos tributarios, sino crear conciencia tributaria, mejorar el comportamiento del contribuyente, el nivel de control de la administración tributaria, reducir la evasión tributaria (p. 42).

No obstante, Castro (2015) indica que "la evasión fiscal no ha sido posible eliminarla totalmente, constituyendo un problema grave para el estado ecuatoriano" (p.12). Este problema se profundiza por la caída en los precios del petróleo y la dependencia absoluta que tiene el estado ecuatoriano actualmente sobre éste.

Por otra parte, la evasión fiscal también se refiere a contribuyentes que evitan pagar sus impuestos de manera total o parcial y, que por ley están obligados hacerlo; esto impacta fuertemente en la economía ecuatoriana, ocasionando pérdidas efectivas a los ingresos que el fisco espera recibir para su funcionamiento.

El art. 284 de la Constitución Política de la República del Ecuador se enuncia que, la política 
económica tendrá los siguientes objetivos alineados con la recaudación tributaria:

- Asegurar una adecuada distribución del ingreso y de la riqueza nacional.

- Lograr un desarrollo equilibrado del territorio nacional, la integración entre regiones, en el campo, entre el campo y la ciudad, en lo económico, social y cultural.

Para ello se utilizan instrumentos como la política fiscal, que tiene que ver con la aplicación de una serie de medidas que permiten al estado la recaudación necesaria de dinero para su funcionamiento y el cumplimiento de sus fines sociales.

Además, el art. 285 indica que la política fiscal tendrá como objetivos específicos:

- El financiamiento de servicios, inversión y bienes públicos.

- La redistribución del ingreso por medio de transferencias, tributos y subsidios adecuados.

- La generación de incentivos para la inversión en los diferentes sectores de la economía y para la producción de bienes y servicios, socialmente deseables y ambientalmente aceptables.

El régimen tributario está diseñado para recaudar los recursos necesarios para proveer la redistribución de la riqueza, estimulará el empleo, la producción de bienes y servicios, conductas ecológicas, sociales y económicas responsables con la premisa; el que más tiene, más paga.

El art. 286 detalla que las finanzas públicas, en todos los niveles de gobierno, se conducirán de forma sostenible, responsable y transparente y procurarán la estabilidad económica. Los egresos permanentes se financiarán con ingresos permanentes. Los egresos permanentes para salud, educación y justicia serán prioritarios y, de manera excepcional, podrán ser financiados con ingresos no permanentes.

El art. 287 nos indica que: "toda norma que cree una obligación financiada con recursos públicos establecerá la fuente de financiamiento correspondiente. Solamente las instituciones de derecho público podrán financiarse con tasas y contribuciones especiales establecidas por ley" (p. 92).

Del mismo modo, la sección 5 del art. 300 determina que "el régimen tributario se regirá por los principios de generalidad, progresividad, eficiencia, simplicidad administrativa, irretroactividad, equidad, transparencia y suficiencia recaudatoria. Se priorizarán los impuestos directos y progresivos".

El Código Tributario Ecuatoriana en el art. 2.- trata sobre la supremacía de las normas tributarias, las cuales estarán sobre todas las normas de leyes generales. En consecuencia, no serán aplicables por la administración ni por los órganos jurisdiccionales las leyes y decretos que de cualquier manera contravengan este precepto.

Y, por último, el art. 6 señala que los tributos además de ser medios para recaudar ingresos públicos, servirán como instrumento de política económica general, estimulando la inversión, la 
reinversión, el ahorro y su destino hacia los fines productivos y de desarrollo nacional; atenderán a las exigencias de estabilidad y progreso sociales y procurarán una mejor distribución de la renta nacional (p. 2).

El Consejo Nacional de Planificación (2009) plantea la política 1.5. para asegurar la (re) distribución solidaria y equitativa de la riqueza, ampliar la base de contribuyentes con énfasis en la recaudación de tributos no regresivos, fundamentados en el principio de justicia distributiva. Entre estos se destacan:

- Fortalecer la cultura tributaria del país a través de la difusión del uso de los recursos recaudados en inversión pública.

- Aplicar y fortalecer mecanismos de control y penalización severa al contrabando y la evasión tributaria, particularmente de las personas naturales y jurídicas generadoras de grandes ingresos y utilidades. (p. 145)

Todas estas normas están encaminadas a lograr la suficiencia del sistema tributario como lo sostiene (Godoy Peralta, 2015), quien argumenta que se debe aumentar la capacidad recaudatoria y mejorar la eficiencia de la administración tributaria. La primera de ellas pertenece al ámbito de la política tributaria y que tiene que ver con variables tales como el nivel de las tasas, la amplitud de las bases imponibles, el nivel de las sanciones, etc. La segunda que es la eficiencia de la administración se relaciona con el objeto de reducir la evasión, para lo cual dispone principalmente de sus facultades de fiscalización (p. 26).

El presupuesto general del estado es el principal instrumento financiero de una nación y está compuesto, según Guaranda (2016), por el ingreso y gastos, para equilibrar las diferencias se recurre al endeudamiento como fuente de financiamiento. La parte del ingreso consta de ingresos corrientes, ingreso de capital e ingresos financieros; el gasto consta de gastos corrientes, gasto de capital y financieros (p. 22).

Pese a esto, del equilibrio entre ingreso público y gasto público depende el buen funcionamiento de la economía (Figura 2). 


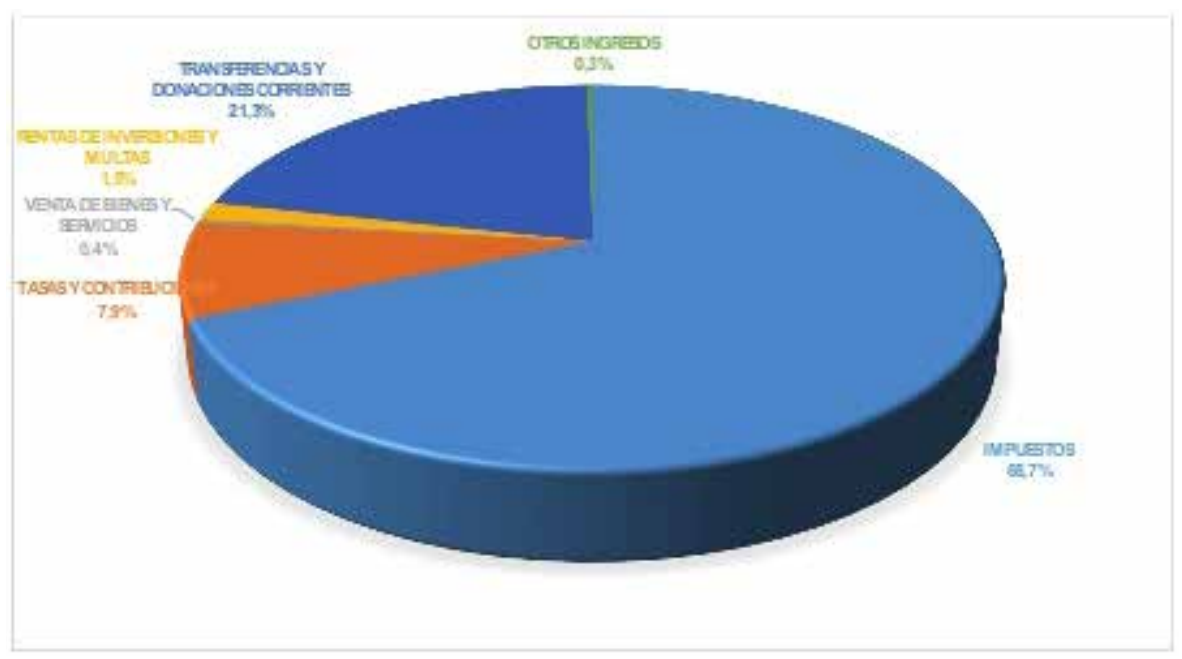

Figura 2. Composición de los ingresos permanentes

Fuente: Comisión de Régimen Económico y Tributario.

Romo (2015) indica que el Presupuesto General del Estado se financia de los ingresos tributarios y no tributarios, de la explotación de petróleo, de la gestión de las Entidades Públicas donaciones, asistencia técnica, préstamos, entre otros. El financiamiento incluye los saldos de ejercicios anteriores no utilizados, las cuentas por cobrar y los recursos provenientes de endeudamiento público y externo (p. 65).

Tabla 2.

Estructura del Ingreso del Presupuesto

\begin{tabular}{|c|c|c|}
\hline \multirow{10}{*}{ Ingreso } & \multirow{5}{*}{ Ingresos corrientes } & Impuestos directos \\
\hline & & Impuestos Indirectos \\
\hline & & Tasa, predios y control de gastos \\
\hline & & \begin{tabular}{|l} 
Transferencias corrientes \\
\end{tabular} \\
\hline & & Ingreso patrimoniales \\
\hline & Ingresos Petroleros & $\begin{array}{l}\text { Exportación de barriles de } \\
\text { petroleo y sus derivados }\end{array}$ \\
\hline & Ingresos de Capital & Enajenacion de Inversión \\
\hline & \multirow{3}{*}{ Ingresos Financieros } & Transferencia de capital \\
\hline & & Activos Financieros \\
\hline & & Pasivos Financieros \\
\hline
\end{tabular}

Fuente: Romo Estrada (2015)

Humanante (2014), respecto de los ingresos petroleros, manifiesta que estos conforman el pilar fundamental para la economía del país, representando este sector la mayor parte de los ingresos que obtiene Ecuador de las exportaciones, estos ingresos forman parte del Presupuesto General del Estado (Tabla 2), y son los que cubren mayormente los egresos del Estado (...) (p. 37).

Por otro lado, los ingresos no petroleros tributarios están constituidos por el cobro de impuestos de aplicación general y administrada por el Servicio de Rentas Internas como, por ejemplo; el impuesto a la renta e impuesto al valor agregado entre otros. Dentro de este grupo igualmente 
tenemos los ingresos provenientes por el cobro de aranceles a importaciones que los controla la Secretaría Nacional de Aduanas del Ecuador. También consta los impuestos, tasas y contribuciones percibidos por los gobiernos seccionales como: municipios y concejos provinciales, entre otros.

El gasto público se puede clasificar en gasto corriente, gasto de capital, pago de deuda, gasto de servicios públicos, gasto social, y gastos de administración del estado. Cabe señalar que desde el año 2009 el presupuesto General del Estado ha ido aumentando sustancialmente, llegando al $14,85 \%$.

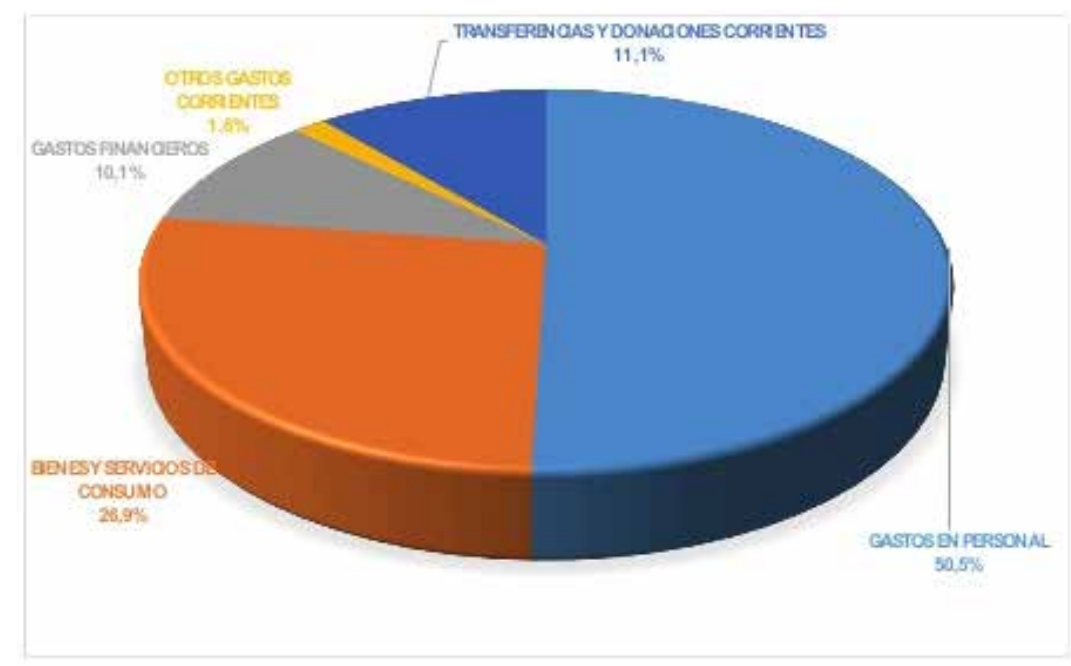

Figura 3. Composición de los gastos permanentes

Fuente: Comisión de Régimen Económico y Tributario - Ministerio de Finanzas

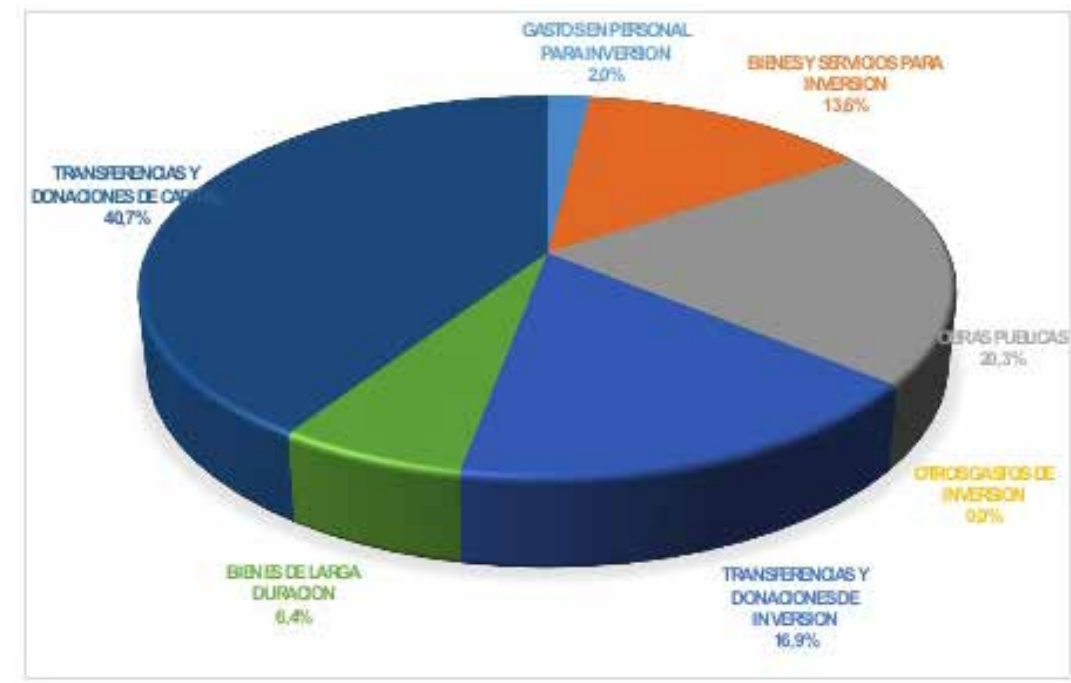

Figura 4. Composición de los gastos no permanentes

Fuente: Comisión de Régimen Económico y Tributario - Ministerio de Finanzas 
El presente trabajo tiene como propósito determinar las razones por las cuales los contribuyentes evaden impuestos en el cantón Pelileo, perteneciente a la provincia del Tungurahua. Se eligió esta localidad por cuanto es la segunda de mayor actividad económica después de la capital provincial Ambato.

\section{Metodología}

El presente artículo se enmarca dentro del tipo de investigación de campo, en vista de que la naturaleza de la información a recolectar nos obliga a realizarlo en el lugar mismo donde se producen los hechos.

Para este trabajo fue imprescindible utilizar métodos lógicos como: el análisis, la síntesis, la deducción y, la inducción. Todos estos métodos lógicos sirven para interpretar la información extraída de la fuente de estudio y encontrar una respuesta a la interrogante planteada.

Se consideró oportuno utilizar el método probabilístico, el mismo que está conformado por el número de contribuyentes que tienen el RUC (Registro único de Contribuyentes) (Tabla 3) en estado pasivo y que; sin embargo, siguen teniendo actividad económica. La razón principal de haber considerado a contribuyentes en estado pasivo radica en que, a criterio de los investigadores, por cómo se planteó el objetivo, se quería evitar el sesgo en la obtención de la información, puesto que, es difícil que un contribuyente en estado activo colabore con este tipo de estudios por el temor que siente solo se escuchar el nombre SRI.

Tabla 3.

Contribuyentes registrados en la base de datos del SRI

\begin{tabular}{|c|c|c|c|c|c|c|c|c|c|}
\hline & & ACTIVO & & PASIVO & & $\begin{array}{l}\text { SUSPEI } \\
\text { DEFINIT }\end{array}$ & & & \\
\hline $\begin{array}{l}\text { Descripción } \\
\text { Provincia }\end{array}$ & Cantón & $\begin{array}{l}\text { Número } \\
\text { de RUC }\end{array}$ & $\begin{array}{l}\text { \% de } \\
\# \text { de } \\
\text { RUC } \\
\text { por } \\
\text { Cantón }\end{array}$ & $\begin{array}{l}\text { Número } \\
\text { de RUC }\end{array}$ & $\begin{array}{l}\text { \% de } \\
\# \text { de } \\
\text { RUC } \\
\text { por } \\
\text { Cantón }\end{array}$ & $\begin{array}{l}\text { Número } \\
\text { de RUC }\end{array}$ & $\begin{array}{l}\% \text { de } \\
\text { \# de } \\
\text { RUC por } \\
\text { Cantón }\end{array}$ & $\begin{array}{l}\text { Total } \\
\text { Número } \\
\text { de RUC }\end{array}$ & $\begin{array}{l}\text { Total \% } \\
\text { Número } \\
\text { de RUC }\end{array}$ \\
\hline Tungurahua & $\begin{array}{l}\text { San Pedro de } \\
\text { Pelileo }\end{array}$ & 5,511 & $8,24 \%$ & 206 & $3,57 \%$ & 2,362 & $5,53 \%$ & 8,079 & $7,00 \%$ \\
\hline
\end{tabular}

Fuente: elaboración propia con Base de datos SRI corte mayo 2012

\subsection{Muestra}

Se trabajó con una muestra probabilística conformada por 125 contribuyentes en estado pasivo del cantón Pelileo, provincia del Tungurahua. La información fue extraída de la base de datos del Servicio de Rentas Internas. La fórmula utilizada para su obtención fue: 


$$
\mathbf{n}=\mathbf{n}=\frac{Z^{2} N p q}{(N-1) E^{2}+Z^{2} p q} \quad \mathrm{n}=\frac{(1,65)^{2}(215)(0,5)(0,5)}{(200-1)(0,05)^{2}+(1,65)^{2}(0,5)(0,5)}
$$

Para la obtención de los resultados se aplicó el Chi Cuadrado $\left(\chi^{2}\right)$ que sirve para establecer la correspondencia entre valores observados y esperados; es decir, a las distribuciones de frecuencias las aplica una prueba de hipótesis.

Se procedió a aplicar una encuesta encaminada a determinar los principales factores que obligan a los contribuyentes a evadir impuestos. Para ello se tomó como referencia las preguntas y respuestas 5 y 9 que están relacionadas con las variables tanto independiente y dependiente.

- ¿Se cuenta con una cultura y conocimiento tributario suficiente por parte de los contribuyentes?

- ¿Piensa que fortalecimiento de la cultura tributaria disminuirá la evasión fiscal?

Tabla 4.

Tabla De Frecuencia Observada (O) y Esperada (E)

\begin{tabular}{|l|l|l|l|l|l|}
\hline CASILLAS X, Y & Fo & Fe & O-E & $(\mathbf{O}-\mathrm{E})^{2}$ & $(\mathbf{O}-\mathrm{E})^{2} / \mathbf{E}$ \\
\hline SI. VARIABLE INDEPENDIENTE & 114 & 72 & 42 & 1764 & 24,5 \\
\hline NO. VARIABLE INDEPENDIENTE & 6 & 48 & -42 & 1764 & 36,75 \\
\hline SI. VARIABLE DEPENDIENTE & 30 & 72 & -42 & 1764 & 24,5 \\
\hline NO. VARIABLE DEPENDIENTE & 90 & 48 & 42 & 1764 & 36,75 \\
\hline $\mathbf{X}^{\mathbf{2}}$ & & & & & 122,5 \\
\hline
\end{tabular}

Fuente: elaboración propia basada en la encuesta realizada a los contribuyentes pasivos

Planteamiento de las Hipótesis (Ho y Ha).

Ho: fo $=<$ fe La cultura tributaria no contribuye significativamente a disminuir la evasión fiscal.

Ha: fo > fe La cultura tributaria contribuye significativamente a disminuir la evasión fiscal.

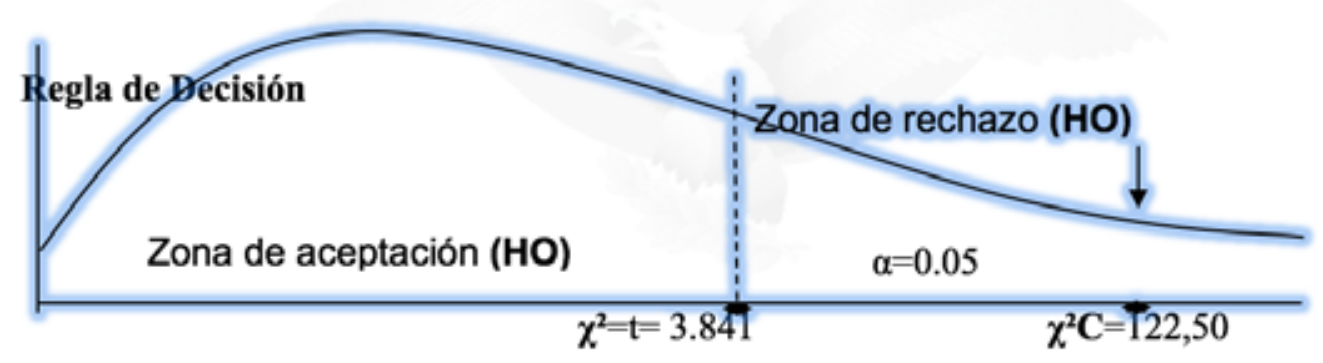

\section{Decisión}

$\chi^{2}$ converge en la zona de rechazo de Ho; por consiguiente, acepto Ha; se confirma que: "la cultura 
tributaria contribuye significativamente a disminuir la evasión fiscal".

\section{Resultados}

Al calcular la tabla de contingencia y consecuentemente el Chi Cuadrado $\chi^{2}$ fue de 122,50. El resultado muestra que existe una estrecha relación entre la cultura tributaria y la evasión fiscal. Demostrando que la hipótesis "la cultura tributaria contribuye significativamente a disminuir la evasión fiscal" es válida.

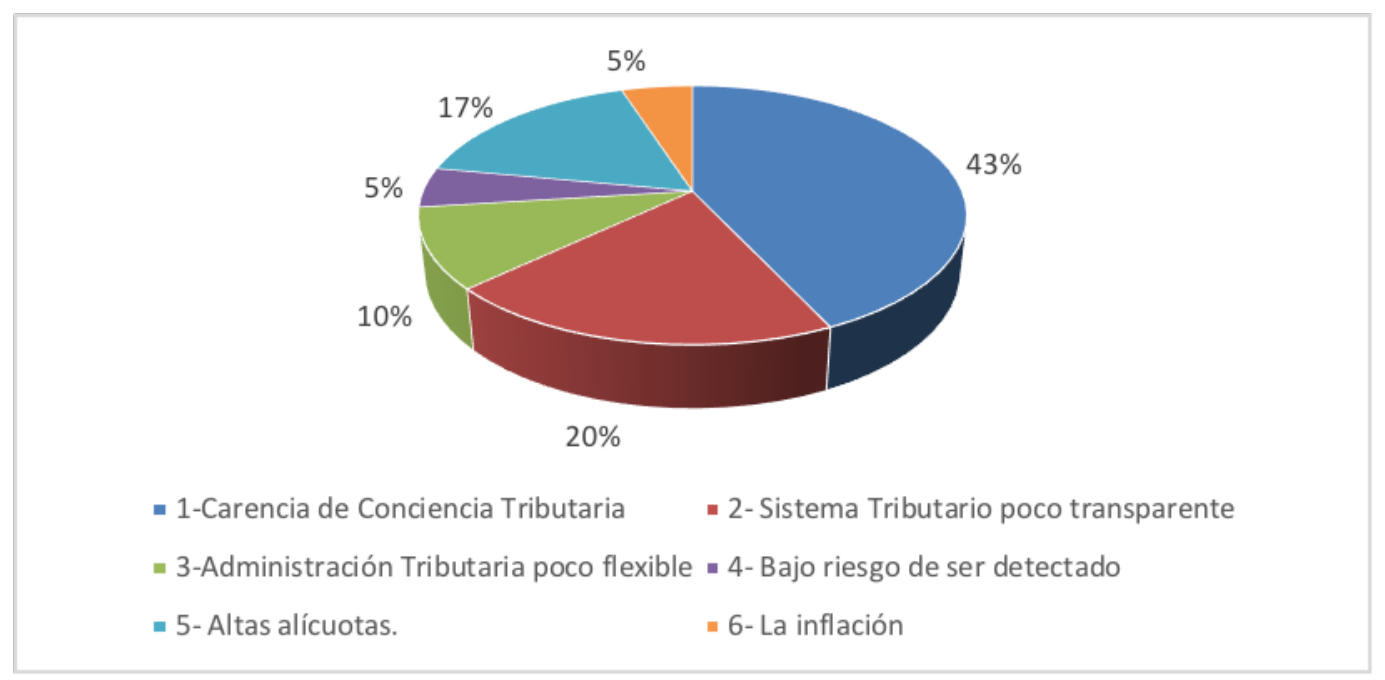

Figura 6. Factores que influyen en el incumplimiento de obligaciones tributarias

Fuente: elaboración propia basada en encuesta realizada a socios

También se nota que el factor más relevante por el cual la gente incumple obligaciones tributarias (Figura 6) es la poca cultura tributaria, seguido de un sistema tributario poco transparente; entendiendo por esta parte como el desconocimiento ciudadano del destino de los impuestos.

\section{Conclusión}

Los resultados del presente estudio se muestran satisfactorios y viables para la implementación de un núcleo de apoyo fiscal que coadyuve a la disminución de la evasión fiscal, fortaleciendo la conciencia tributaria ciudadana.

Este proceso tendría el propósito de lograr una cohesión social mediante la aplicación y mejoras de políticas públicas que contribuyen a lograr una cultura tributaria a todo nivel, a través de la capacitación de la ciudadanía, fortaleciendo de esa manera la conciencia fiscal y sensibilización sobre el tema.

Los resultados obtenidos indican que al mejorar la conciencia tributaria se lograría que cuatro de cada diez personas cumplan con sus obligaciones fiscales; sin embargo, el problema está lejos de resolverse. Aunque se ha avanzado mucho en tema de impuestos, todavía existe una importante brecha fiscal en el país. 
Se debe atacar otras causas como: el malestar que causa en la gente temas como la corrupción y, la percepción de que los impuestos no son revertidos hacia la ciudadanía en obras, sino en cuotas políticas doradas propias del gobierno de turno.

Finalmente, se encontró que la mayor parte de los entrevistados aseguran no cumplir con su obligación tributaria por desconocimiento; además se determinó que, en la ciudad predominan dos tipos de evasión tributaria:1) la informalidad y, 2) la no emisión de comprobantes de venta al momento de realizar una transacción económica. 


\section{Referencias}

Asamble Nacional Consituyente. (2008). Constitución de la República del Ecuador. Quito.

Castañeda Rodríguez, V. M. (2015). La moral tributaria en América Latina y la corrupción como uno de sus determinantes. Revista Mexicana de Ciencias Políticas y Sociales, 30.

Castro Washco, T. L. (2015). Análisis de las reformas tributarias e incidencia en la recaudación de los principales impuestos del ecuador. 2009 - 2013. Cuenca.

Centro de Estudios Fiscales. (2014). Quito. Obtenido de https://cef.sri.gob.ec/virtualcef/mod/book/view.php?i$\mathrm{d}=1121$ \& chapterid $=744$

Chelala, S., \& Giarrizzo, V. (2014). Evasión de impuestos en Argentina: un análisis experimental de la eficiencia de premios y castigos al contribuyente. Revista Finanzas y Política Económica, 19. https://doi. org/10.14718/revfinanzpolitecon.2014.6.2.3

Comisión Económica para América Latina y el Caribe. (2020). América Latina y el Caribe: el aumento de los ingresos tributarios se ve amenazado en medio del deterioro de las perspectivas regionales. Santiago de Chile.

Consejo Nacional de Planificación. (2009). Plan Nacional para el Buen Vivir. Quito: SEMPLADES.

Del Valle Santander, E. (2010). Factores de la Evasiòn Fiscal. Revista de Ciencias Economicas OIKONOMOS, 12.

Dirección Nacional Jurídica de Ecuador. (2014). Código Tributario. Quito.

El Telégrafo. (s.f.). Cómo afecta la evasión tributaria al desarrollo de un Estado. Quito. Obtenido de https://www. eltelegrafo.com.ec/noticias/politica/2/ecuador-pierde-entre-usd-300-y-usd-400-millones-anuales-por-evasion-fiscal

Godoy Peralta, M. G. (2015). Desarrollo de la cultura tributaria en el Ecuador y su impacto en la recaudación tributaria. Período: 2011-2014. Guayaquil.

Gómez Sabaini, J. C. (2016). Evasión tributaria en América Latina: nuevos y antiguos desafíos en la cuantificación del fenómeno en los países de la región. Amèrica Latina.

Guaranda Quijijie, H. F. (2016). El impuesto a la salida de divisas y el presupuesto general del estado en el Ecuador, periodo 2010 - 2014. Guayaquil.

Humanante Serrano, A. D. (2014). Análisis comparativo entre los ingresos petroleros y los ingresos tributarios y 
su distribución en el Presupuesto General del Estado 2008-2012. Guayaquil.

Quintanilla De la Cruz, E. (2014). La evasión tributaria y su incidencia en la recaudación fiscal en el Perú y Latinoamérica. Lima.

Raymond Bara, J. L. (1997). Tipos de Evasión Impositiva en España, un analisis empírico tipos de economía española. Madrid.

República del Ecuador. (s.f.). Constitución Política de la República del Ecuador. Quito.

Romo Estrada, J. (2015). Las reformas tributarias del gobierno del Eco. Rafael Correa Delgado, su impacto en el Presupuesto General del Estado y en la redistribución de la riqueza. Período 2007-2013. Guayaquil. 